\title{
Proportions of Cancer Deaths Attributable to Cigarette Smoking in Women
}

\author{
Steven D. Stellman, PhD \\ Lawrence Garfinkel, MA
}

\begin{abstract}
Over two-thirds of a million American women mostly over age 45 were enrolled in a prospective mortality study in 1982 and followed up for four years. In this time period 1,527 women died of six smoking-related cancer sites: oral cavity, esophagus, pancreas, larynx, lung, and bladder. Age-adjusted death rates in nonsmokers were used to obtain smoking-attributable risks and numbers of deaths due to these six cancers. Among current smokers, 601 deaths (85.5\% of current smokers' deaths) were attributable to cigarette smoking, and among former smokers 284 (69.3\% of exsmokers' deaths) were attributable to smoking. Cigarette smoking accounted for 885 excess deaths at these sites, giving a populationattributable risk of $57.9 \%$. Over three-quarters of these excess deaths were due to lung cancer. Cigarette smoking, despite increases in smoking cessation, is still responsible for well over half of the deaths from these six types of cancer in women.
\end{abstract}

\section{INTRODUCTION}

Despite the fact that cigarette smoking has been firmly established as a causative factor in mortality from many diseases in women, the female death rates from lung cancer and other smokingrelated illnesses are continuing to increase (Devesa, 1986). Control

Steven D. Stellman is with the Division of Biostatistics \& Epidemiologic Research, New York City Department of Health, 125 Worth Street, Box 22, New York, NY 10013. Lawrence Garfinkel is with the Department of Epidemiology \& Statistics, American Cancer Society, 1180 Avenue of the Americas, New York, NY 10036.

Women \& Health, Vol. 15(2) 1989

(C) 1989 by The Haworth Press, Inc. All rights reserved. 
of this major public health problem can be accomplished by three strategies: educating young women and girls not to start smoking, persuading current smokers to quit smoking, and to a lesser extent, reducing the toxicity of cigarettes. All of these approaches require societal determination to deal with the smoking and health problem. Up-to-date, quantitative information concerning the magnitude of health risks associated with smoking plays a key role in setting public health priorities and developing smoking reduction strategies. Such information is useful in determining the number of cases of various diseases that smoking actually causes, and in estimating the costs to individuals, to families, and to society, which those diseases create.

We present here a set of estimates of the proportion of cancer deaths that are attributable to cigarette smoking, based upon observations in a cohort of approximately two-thirds of a million American women enrolled in 1982 and followed prospectively for four years.

\section{METHODS AND MATERIALS}

In the fall of 1982 , more than 77,000 ACS volunteer "researchers" enrolled over 1.2 million men and women in a long-term prospective study (Stellman \& Garfinkel, 1986). Those enrolled, who were usually friends, neighbors or relatives of the volunteers, completed a four-page confidential questionnaire on history of cancer and other diseases; occupational exposures; and a variety of personal habits, including smoking. Enrollment was by family groups with at least one person in the household 45 years of age or older. All members of the household over 30 years of age were asked to complete a questionnaire.

Enrollment of subjects was carried out in all 50 states, the District of Columbia, and Puerto Rico. It began in September, 1982, and was essentially completed by the end of November, 1982. Every second year each researcher is sent a list of the persons he or she enrolled and is asked to check whether those enrollees are alive or dead; if dead, the researcher records the date and place of death. Death certificates are subsequently obtained through state health departments. Follow-ups were completed in 1984 and 1986; a third follow-up started in September, 1988. 
Causes of death were coded to a modified version of the Ninth Revision of the International Classification of Diseases. Whenever cancer was mentioned on a death certificate, an attempt was made to obtain information from a physician, hospital, or tumor registry concerning the basis for diagnosis. To date about $25 \%$ of such requests have been answered; this phase of the study is still in progress. For cancers only, cause of death is therefore based upon the best evidence currently available.

A total of 685,748 women were initially enrolled. A small proportion of these were found to be ineligible (too young) or had contributed unusable questionnaires. The smoking habits of the remaining 676,640 women have previously been presented in some detail. Of these women, $52.5 \%$ had never smoked cigarettes regularly, $42.4 \%$, had smoked at some time, and $5.0 \%$ could not be classified as to smoking habit; among ever-smokers, $1.9 \%$ could not be classified as current or former smokers. The present analysis is based upon those 619,925 female enrollees whose exact smoking status at time of enrollment was known, and whose vital status as of September, 1986, had been determined.

Each subject was classified into exactly one of eleven mutually exclusive smoking categories: never smoked regularly (N.S.R.), current smoker of $1-10,11-19,20,21-30$, or 31 or more cigarettes daily, or former smokers of $0-2,3-5,6-10,11-15$, or 16 or more years' cessation. Within each of these eleven categories age-specific mortality rates were computed by dividing the number of deaths from a given cause by the person-years of experience observed for women in that age-smoking-specific stratum. Personyears of observation were allocated by single years of attained age, and then grouped into eleven age categories: $30-39$ years, $40-44$, $45-49, \ldots 80-84$, and 85 and older. All computations were thus based upon the ages actually attained at the time of the observation, so that each person-years age stratum is composed of contributions from women who reached that age group at some time during the follow-up, and numerators for death rates are based upon the women's ages at death. Since all observations were contemporaneous, no adjustment for calendar year is needed.

Death rates were directly adjusted to the age distribution of the $2,446,435$ person-years experienced by the entire cohort of 619,925 women. Within any smoking stratum, the relative risk for death 
from a particular cause is the age-adjusted rate for that cause divided by the corresponding death rate among nonsmokers.

Two types of attributable risks were computed. The categoryattributable risk for a specific smoking category (such as current smokers of 20 cigarettes per day) is the difference between the death rate within that smoking category and the rate in nonsmokers. The category-attributable risk percent is that difference divided by the category-specific rate, expressed as a percent. Multiplying this percent by the number of deceased subjects who initially identified themselves as smokers at that level yields the number of categoryattributable deaths.

The population-attributable risk (P.A.R\%) is the number of attributable deaths from all smoking categories combined, divided by the total number of deaths in the cohort, expressed as a percent. The P.A.R\% is commonly interpreted as an estimate of the proportion of deaths within a population from a given cause which are attributable to the exposure in question, and, by extension, the proportion of deaths which could be prevented by eliminating that exposure in the population (Lilienfeld \& Lilienfeld, 1980).

Attributable risk computations were made for six sites of cancer which are generally recognized as causally related to cigarette smoking: oral cavity (ICD-9 140-149), esophagus (150), pancreas (157), larynx (161), lung (162), and bladder (188). These are the only cancer sites which were significantly elevated among current smokers compared to nonsmokers. Other cancer sites have also been linked to cigarette smoking in the literature, such as stomach and kidney, but these rates were not significantly elevated among women smokers in this population. In a few categories the death rate for smokers was slightly below that for nonsmokers, due in all probability to small numbers of observations and statistical variation. The attributable risk in such cases was taken to be zero.

\section{RESULTS}

Table 1 shows the distribution of age and person-years in the study population, along with the distribution of smoking habits. The mean age at enrollment was 57 years, and the women were followed for an average of 3.95 years.

The attributable risk results are shown in detail for lung cancer in 
TABLE 1

\begin{tabular}{|c|c|c|c|c|c|}
\hline \multirow[t]{2}{*}{$\begin{array}{l}\text { Age } \\
\text { Group }\end{array}$} & $\begin{array}{c}\text { Number of } \\
\text { women }\end{array}$ & $\begin{array}{c}\text { Never } \\
\text { Smoked } \\
\text { Regularly }\end{array}$ & $\begin{array}{l}\text { Current } \\
\text { Smoker }\end{array}$ & $\begin{array}{l}\text { Former } \\
\text { Smoker }\end{array}$ & $\begin{array}{l}\text { Person- } \\
\text { Years }\end{array}$ \\
\hline & & \multicolumn{4}{|c|}{ Percentage } \\
\hline $\begin{array}{l}30-39 \\
40-44 \\
45-49 \\
50-54 \\
55-59 \\
60-64 \\
65-69 \\
70-74 \\
75-79 \\
80-84 \\
85+\end{array}$ & $\begin{array}{r}32579 \\
45694 \\
93496 \\
206812 \\
107244 \\
90064 \\
66175 \\
41848 \\
22031 \\
9074 \\
4908\end{array}$ & $\begin{array}{l}51.8 \\
50.3 \\
51.1 \\
52.5 \\
54.3 \\
58.0 \\
60.2 \\
66.7 \\
75.7 \\
83.2 \\
90.2\end{array}$ & $\begin{array}{r}27.3 \\
25.9 \\
25.7 \\
24.3 \\
22.6 \\
19.8 \\
17.2 \\
13.3 \\
9.0 \\
6.0 \\
3.4\end{array}$ & $\begin{array}{r}20.9 \\
23.8 \\
23.2 \\
23.2 \\
23.0 \\
22.2 \\
22.6 \\
20.0 \\
15.3 \\
10.8 \\
6.4\end{array}$ & $\begin{array}{r}130020 \\
182312 \\
372470 \\
424903 \\
425386 \\
355594 \\
259391 \\
162374 \\
84091 \\
33603 \\
16291\end{array}$ \\
\hline Total & 619925 & & & & 2446435 \\
\hline
\end{tabular}

Table 2. As an example, the age-standardized lung cancer rate among women who were currently smoking 20 cigarettes per day when they were enrolled in CPS-II was 152.86 , whereas the agestandardized rate in nonsmoking women was 11.46 (Table 2). The relative risk for one-pack-a-day smokers is therefore $152.86 / 11.46$ or 13.3 , and the attributable risk is $152.86-11.46=141.40$. The attributable risk percent for one-pack-a-day smokers is $141.40 /$ $152.86=92.5 \%$, and the attributable number of deaths in this category alone is $92.5 \%$ of the 203 observed deaths, or about 188 deaths. This may be viewed as the number of excess deaths from lung cancer which would not have occurred if the women who described themselves as one-pack-a-day smokers had never smoked cigarettes.

The foregoing calculation was applied separately to each of the ten categories of current and former smokers and the number of attributable deaths within each category was thereby calculated. There were 487.1 excess or attributable deaths among current smokers, which represents $487.1 / 530=91.9 \%$ of lung cancer deaths among current smokers. Similarly, the attributable risk percent among former smokers was $207.9 / 262=79.4 \%$, and for all smokers combined was $695.0 / 792=87.8 \%$, which is the percentage of lung cancer deaths among smokers attributable to their habit. 


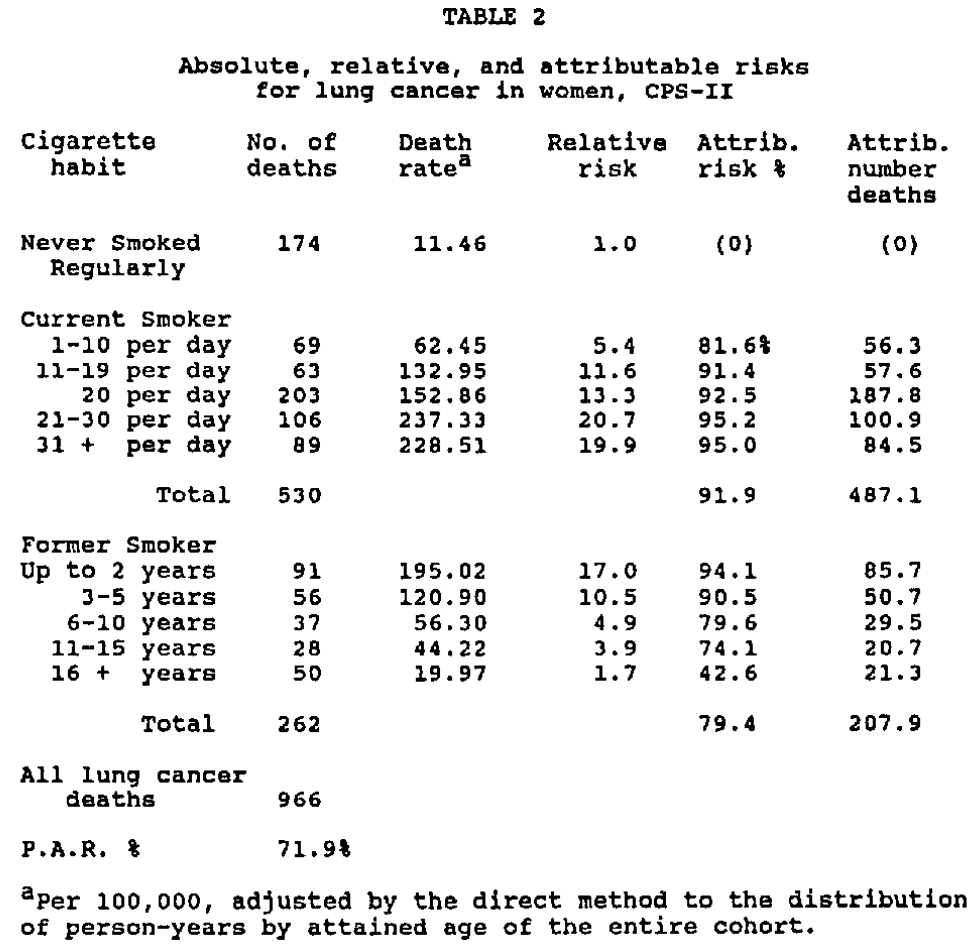

Finally, there were 966 lung cancer deaths in all women (smokers plus nonsmokers), giving a P.A.R. $\%$ of $695.0 / 966=71.9 \%$. This is the proportion of lung cancer deaths in the entire CPS-II female population which may be attributable to cigarette smoking, or, alternatively, the proportion of lung cancer deaths which would never have occurred if none of these women had smoked.

Corresponding attributable risks were computed for cancer of the oral cavity, esophagus, pancreas, larynx, and bladder. The data for all six cancer sites individually and combined are summarized in Table 3. From these data it is evident that the attributable risk among current smokers ranged from $55.2 \%$ (pancreatic cancer) to 92.9\% (laryngeal cancer); among ex-smokers it ranged from $42.4 \%$ (pancreatic cancer) to $92.9 \%$ (laryngeal cancer). These are, according to our interpretation, the proportions of deaths from these six 
TABLE 3

Number and percent of cancer deaths in women attributable to cigarette smoking, by smoking exposure and cancer site

CANCER SITE

Oral
Cavity Esophagus Pancreas Larynx Lung Bladder

All

Sites

Current Smokers

Smoking-attributable

- Total deaths

$\begin{array}{lllllll}24.5 & 21.5 & 51.3 & 6.5 & 487.1 & 9.6 & 600.5 \\ 30 & 25 & 93 & 7 & 530 & 17 & 702 \\ 81.7 & 86.0 & 55.2 & 92.9 & 91.9 & 56.5 & 85.5\end{array}$

Former Smokers

Smoking-attributable deaths

Total deaths

Percent

$\begin{array}{lllllll}14.1 & 8.9 & 38.2 & 6.5 & 207.9 & 8.4 & 284.0 \\ 21 & 13 & 90 & 7 & 262 & 17 & 410 \\ 67.1 & 68.5 & 42.4 & 92.9 & 79.4 & 49.4 & 69.3\end{array}$

\section{Non-smokers}

Total deaths

22

13

166

2

174

38

415

All Subjects

Smoking-attributable deaths

Total deaths

$$
73
$$

30.4

$$
\begin{gathered}
89.5 \\
349
\end{gathered}
$$

13.0

695.0

18.0

884.5

P.A.R., \% $52.9 \% \quad 59.6 \% \quad 25.6 \%$

$813 \%$

$71.9 \% \quad 25.0 \% \quad 57.9 \%$

types of cancer which could have been avoided or prevented if women who smoked had never started. The P.A.R.\%, which takes into account the prevalence of smoking in the entire study population, ranged from $25.0 \%$ for bladder cancer to $81.3 \%$ for cancer of the larynx. For the other cancer sites the P.A.R.\%s were $52.9 \%$ (oral cavity), $59.6 \%$ (esophagus), $25.6 \%$ (pancreas), and $71.9 \%$ (lung). The P.A.R.\% for the six sites combined was $57.9 \%$.

\section{DISCUSSION}

Tobacco use continues to be a leading public health problem worldwide, for women as well as men (Zaridze \& Peto, 1986). In 1980 , cigarette smoking was estimated to be responsible for over one-fourth of all 231,000 cancer deaths in U.S. women (Office on 
Smoking and Health, 1980), or about 60,000 deaths annually. Just the six cancer sites which we studied account for about 68,000 deaths per year in women (American Cancer Society, 1988), so that if the P.A.R.\% of $57.9 \%$ observed in the CPS-II population applied to the entire U.S. female population, we would calculate that cigarette smoking accounts for over 40,000 deaths from these six types of cancer. Even allowing for differences between CPS-II women and the general population which limit the generalizability of results (Stellman \& Garfinkel, 1986), it is unlikely that the true population attributable risk for these six cancers is below one-half. In other words, cigarette smoking causes at least $35-40,000$ preventable cancer deaths in American women each year, in addition to deaths from heart disease, stroke, and other causes not considered in this paper.

Our results are consistent with attributable risks calculated by others, such as 75\% for lung cancer (Doll \& Peto, 1981), 30-40\% for bladder cancer (Wynder \& Goldsmith, 1977), and 30\% for pancreatic cancer (Office on Smoking and Health, 1982). Our computations are more detailed than many in the previous literature because they take into account the actual quantities of cigarettes smoked by current smokers, as well as years of cessation by exsmokers, and it is therefore possible that they are more accurate.

The concept of attributable risk, though attractive because of its simplistic interpretation, has the drawback of being one-dimensional. That is, it takes no account of other risk factors for lung cancer such as occupational exposures, nutrition, etc. It especially ignores the possibility of interactions, or synergism, and therefore has the potential for overstating the contribution of smoking relative to other contributing causes. This may be especially important in the cases of the three cancer sites which are closely associated with heavy alcohol consumption: esophagus, oral cavity, and larynx (Wynder \& Stellman, 1977; Stellman, 1986a). Smoking-related cancer deaths today reflect smoking habits begun many years ago and continued over a period of decades. In 1955, 24.5\% of women smoked. The prevalence of smoking in women peaked at $34.1 \%$ in 1965 , but has declined only gradually since then to $28 \%$ in 1985 . By contrast, men hit a much higher peak, $52.9 \%$ in 1964, and are now down to 33\% (Office on Smoking and Health, 1987). A grad- 
ual decline can only mean that the unacceptably high rate of cigarette-related cancer deaths will continue well into the future. Furthermore, the long latency period of all types of cancer implies that even a successful, intensive effort at persuading smokers to quit can have only a gradual effect on population attributable risks over the short run, and even so there are new problems to contend with. Girls are starting to smoke earlier now than in the past, so that high school girls today are more likely to be smokers than are high school boys (Office on Smoking and Health, 1987). Moreover, as Virginia Ernster has documented in this Journal, women have been increasingly targeted by tobacco companies for advertising and promotion of new brands (Ernster, 1986). In the most pessimistic view, these trends may offset the modest declines in prevalence among adults. Nevertheless, major gains are being made in social control of cigarette smoking, which may affect death rates as this century comes to a close. Low tar/nicotine cigarettes are now the rule rather than the exception, and may lead to lower lung cancer rates in smokers (Stellman, 1986b). Research into gender differences is improving smoking cessation techniques (Orlandi, 1986). Finally, increased concern over health effects of passive smoking have led to a world-wide movement to restrict smoking in public places, offices, and elsewhere (Stellman \& Papier, 1986). These social, scientific, and legislative activities are considerably aided by continuing research into current disease risks among smokers.

\section{REFERENCES}

American Cancer Society. (1988) Facts and Figures, 1988. New York: American Cancer Society.

Devesa, S.S. (1986) Cancer mortality, incidence, and patient survival among American women. Women \& Health 11:7-22.

Doll, R. \& Peto, R. (1981) The Causes of Cancer: Quantitative Estimates of Avoidable Risks of Cancer in the United States Today. New York: Oxford University Press.

Enster, V.L. (1986) Women, smoking, cigarette advertising and cancer. Women \& Health 11:217-235.

Lilienfeld, A.M. \& Lilienfeld, D.E. (1980) Foundations of Epidemiology, 2nd Ed. New York: Oxford University Press.

Office on Smoking and Health. (1980) The Health Consequences of Smoking for Women. A Report of the Surgeon-General. Rockville, MD: Office on Smok- 
ing and Health, Public Health Service, U.S. Department of Health and Human Services.

Office on Smoking and Health. (1982) The Health Consequences of Smoking. Cancer. A Report of the Surgeon-General. Rockville, MD: Office on Smoking and Health, Public Health Service, U.S. Department of Health and Human Services.

Office on Smoking and Health. (1987) Smoking and Health: A National Status Report. (DHHS Pub. No. 87-8396). Rockville, MD: Office on Smoking and Health, Public Health Service, U.S. Department of Health and Human Services.

Orlandi, M.A. (1986) Gender differences in smoking cessation. Women \& Health 11:237-251.

Papier, C.M. \& Stellman, S.D. (1986) Health risks of passive smoking. Women \& Health 11:267-277.

Stellman, S.D. (1986a) Interactions Between Smoking and Other Exposures: Occupation and Diet. In Hoffmann, D., \& Harris, C. (Eds.). Banbury Report No. 23. Mechanisms in Tobacco arcinogenesis. Cold Spring Harbor Laboratory, pp. 377-393.

Stellman, S.D. (1986b) Cigarette Yield and Cancer Risk: Evidence from CaseControl and Prospective Studies. In Zaridze D.G \& Peto, R. (Eds.). Tobacco, A Major International Health Hazard. IARC Scientific Publication No. 74. Lyon: International Agency for Research on Cancer. pp. 197-209.

Stellman, S.D. \& Garfinkel, L. (1986) Smoking habits and tar levels in a new American Cancer Society prospective study of 1.2 million men and women. J Natl Cancer Inst 76:1057-1063.

Wynder, E.L. \& Goldsmith, R. (1977) The epidemiology of bladder cancer. A second look. Cancer 40:1246-1268.

Wynder, E.L. \& Stellman, S.D. (1977) Comparative epidemiology of tobaccorelated cancers. Cancer Res. 37:4608-4622.

Zaridze, D., \& Peto, R. (Eds.) (1986) Tobacco: A Major International Health Hazard. IARC Scientific Publication No. 74. Lyon: International Agency for Research on Cancer. 